\title{
Analysis of Factors Related to Re-Utilization of Health Care by Hypertension Patient in Polyclinic of Internal Medicine in Datu Sanggul Rantau Hospital
}

\author{
Akhmad Munawar Fu'adi", Roselina Panghiyangani ${ }^{* *}$, Fauzie Rahman ${ }^{* * *}$, Husaini ${ }^{*}$, Meitria Syahadatina \\ Noor $^{* * * * *}$ \\ ${ }^{*}$ Master of Public Health, Faculty of Medicine, Lambung Mangkurat University, Indonesia \\ ** Department of Biomedicine, Faculty of Medicine, Lambung Mangkurat University, Indonesia \\ **** Department of Health Care Management, Public Health Study Program, Faculty of Medicine, Lambung Mangkurat University, Indonesia \\ ***** Department of Public Health, Faculty of Medicine, Lambung Mangkurat University, Indonesia \\ DOI: 10.29322/IJSRP.10.08.2020.p104124 \\ http://dx.doi.org/10.29322/IJSRP.10.08.2020.p104124
}

\begin{abstract}
The health care is an essential element in every hospital. The number of visitors at the polyclinic of internal medicine in Datu Sanggul Rantau Hospital was 6906 which is categorized in high utilization, but based on the results of public satisfaction surveys in 2018 on the outpatient unit obtained the results the interval public satisfaction surveys ranged from 2.60 to 3.064 which is the quality of service performance of units of service are less good. This research aims to analyze the factors that relate to the re-utilization of health care by patients with hypertension at the polyclinic of internal medicine in the hospital of Datu Sanggul Rantau. This study uses a quantitative approach with a crosssectional design. The number of samples in the study was 106 samples with a purposive sampling method. The results showed there was a relationship between completion time $(p=0.021)$, service products $(p=0,000)$, facilities $(p=0.005)$ with the reutilize of health services by hypertension patients in polyclinic of internal medicine in Datu Sanggul Hospital Rantau. There was no relationship between infrastructure $(\mathrm{p}=0.698)$ with the re-utilize of the health services by hypertensive patients in the polyclinic of internal medicine in Datu Sanggul Hospital Rantau. Factors related to the re-utilize of health services by hypertension patients in the polyclinic of internal medicine in Datu Sanggul Hospital Rantau are completion time, facilities, and service products. Service product is the most dominant variable in the re-use of health services by hypertension patients in polyclinic of internal medicine in Datu Sanggul Hospital Rantau.
\end{abstract}

Index Terms- completion time resolution, product service, facilitiy, infrastructure, utilization, health service

\section{INTRODUCTION}

$\mathrm{D}$ ata obtained from the Indonesian Basic Health Research in 2018 states that the prevalence of hypertension in Indonesia is $34.1 \%$, for the population in South Kalimantan Province that is equal to $44.1 \%$ (1). The increasing prevalence of hypertension in Tapin District can be seen from the utilization of health services in Datu Sanggul Hospital Rantau. The results of the 2017 annual report for the number of longtime visitors to the internal medicine polyclinic were 6,906 (2). Outpatient health care is the backbone of the health care system. Outpatient services are the main entry point for residents who need health services (3). The strategic plan of Datu Sanggul Regional Hospital Rantau is stated in strategic issues. One of which is that public trust in private hospitals is higher than in government hospitals, which requires optimal handling. One of the efforts that must be made in improving public services is to conduct a public satisfaction survey (SKM) to service users by measuring the satisfaction of service users. Internal medicine polyclinic is a public service unit in government agencies that directly or indirectly provide services to service recipients (4).

Based on the results of SKM in 2018 conducted by the Datu Sanggul Regional Hospital community satisfaction index in July September 2018 at the Datu Sanggul Regional Hospital on an outpatient installation based on measurements on the quality of 9 service elements, the results of the SKM score of 76.17, but for the process of creating higher-quality public services, the 9 elements of service in the SKM element must be improved again in outpatient polyclinics especially the average of SKM was only 2.60 for completion time, 2.98 for service products and 2.70 for infrastructure facilities wherein the SKM interval value 2.603.064 was the quality of service was not good (5). The length of waiting time for services in the outpatient unit illustrates the performance and quality of hospital services to its customers (6). To keep patients choosing service products in the nerve polyclinic, the hospital must be able to meet the needs of patients so that satisfaction appears, in realizing a good level of customer satisfaction needs to be understood about customer expectations by the service provider (7). According to Wulandari (2016) that there is a significant relationship between facilities and the utilization of health services (8).

Based on the background and identification of the problems above, the problem formulated in this study is the analysis of factors related to the re-utilization of the health services by hypertensive patients in the polyclinic of internal medicine in Datu 
Sanggul Hospital Rantau.

\section{RESEARCH METHOD}

This type of research is an observational analytic study using a quantitative approach with analytic surveys with a cross-sectional design. The population in this study were all hypertensive patients who registered and utilized the service in the disease clinic in Datu Sanggul Rantau Regional Hospital. The sampling method used was purposive sampling. The statistical analysis used is descriptive analysis and inferential statistical analysis.

\section{FINDINGS}

Table 1. The Univariate Analysis Results

\begin{tabular}{llcc}
\hline Variable & \multicolumn{1}{c}{ Category } & Freq & \% \\
\hline Completion time & On time & 55 & 51.9 \\
\hline & Not on time & 51 & 48.1 \\
\hline Product service & Well & 79 & 74.5 \\
\hline & Less & 27 & 25.5 \\
\hline Facilities & Complete & 74 & 69.8 \\
\hline & Not complete & 32 & 30.2 \\
\hline Infrastructure & Complete & 99 & 93.4 \\
\hline & Not complete & 7 & 6.6 \\
\hline
\end{tabular}

Table 2. Bivariate Analysis with Chi-Square

\begin{tabular}{lllll}
\multirow{2}{*}{ Variable } & \multicolumn{2}{c}{$\begin{array}{l}\text { Re-Utilization Health } \\
\text { Service }\end{array}$} & & p-value \\
\cline { 2 - 3 } & $\begin{array}{l}\text { Less Util } \\
\text { ize }\end{array}$ & $\begin{array}{c}\text { Utilize } \\
\text { More }\end{array}$ & \\
& N $\%$ & N $\%$ &
\end{tabular}

\section{Completion time}

\begin{tabular}{|c|c|c|c|c|c|c|}
\hline On time & 39 & 70.9 & 16 & 29.1 & 55 & 0.021 \\
\hline Not on time & 24 & 47.1 & 27 & 52.9 & 51 & \\
\hline \multicolumn{7}{|c|}{ Product service } \\
\hline Well & 37 & 46.8 & 42 & 53.2 & 79 & 0.000 \\
\hline Less & 26 & 96.3 & 1 & 3.7 & 27 & \\
\hline
\end{tabular}

Facilities

\begin{tabular}{lcccccc}
\hline Complete & 37 & 50.0 & 37 & 50.0 & 74 & 0.005 \\
\cline { 1 - 5 } Not complete & 26 & 81.3 & 6 & 18.8 & 32 &
\end{tabular}

Infrastructure

\begin{tabular}{lcccccc}
\hline Complete & 58 & 58.6 & 41 & 41.4 & 99 & \multirow{2}{*}{0.698} \\
\cline { 1 - 5 } Not complete & 5 & 71.4 & 2 & 28.6 & 7 & \\
\cline { 1 - 5 } & & & & &
\end{tabular}

Based on the table above it can be seen that there is a relationship between the completion time ( $\mathrm{p}$-value $=0.021<0.05)$, service products $(\mathrm{p}$-value $=0.000<0.05)$, facilities $(\mathrm{p}$-value $=$ $0.005<0.05$ ) and re-utilization of health services by hypertension patient in the polyclinic of internal medicine in Datu Sanggul Regional Hospital Rantau and there is no relationship between infrastructure ( $\mathrm{p}$-value $=0.698>0.05)$ with the re-utilization of health services by hypertension patient in the polyclinic of internal medicine in Datu Sanggul Regional Hospital Rantau.

Table 3. Multivariate Analysis

\begin{tabular}{|l|c|c|c|c|}
\hline Independent Variable & $\begin{array}{c}\mathrm{p}- \\
\text { value }\end{array}$ & $\begin{array}{c}\text { Exp } \\
(\mathrm{B})\end{array}$ & \multicolumn{2}{|c|}{$95 \%$ CI } \\
\hline Completion time & 0.025 & 0.350 & 0.139 & 0.878 \\
Product Services & 0.002 & 26.587 & 3.300 & 214.177 \\
Facilities & 0.150 & 2.293 & 0.742 & 7.089 \\
\hline
\end{tabular}

Based on the table above, from the final logistic regression analysis, the results show that the product service variable is the most dominant factor related, with a p-value $<0.05$ that is 0.002 and an OR (Odds Ratio) value obtained the largest is 26,587 times providing a strong relationship with the re-utilization of health services by hypertension patient in the polyclinic of internal medicine in Datu Sanggul Regional Hospital Rantau.

\section{DISCUSSION}

Based on table 2 that from the analysis using the chi-square test obtained a p-value of $0.021<0.05$, which means there is a relationship between the time of completion with the re-utilization of health services for patients with hypertension in the polyclinic of internal medicine in Datu Sanggul Regional Hospital Rantau, this study averages completion time on time for 37.4 minutes to 55 respondents, while the average completion time that was not on time was 84.40 minutes to 51 respondents, where the timely completion time provided a good re-utilization of health services, one of which was due because the patient had prior experience for a repeat visit to the polyclinic of internal medicine in Datu Sanggul Regional Hospital Rantau.

Based on table 2 that from the analysis using the chi-square test obtained a p-value of $0.000<0.05$, which means there is a relationship between service products with the re-utilization of health services for hypertensive patients in polyclinic of internal medicine in Datu Sanggul Regional Hospital Rantau. The mechanism of good service products in this study can make people re-utilization health services based on the fact that hypertension patients visiting the internal medicine clinic really want to get health services related to hypertension they suffer where the public perception of service products towards the re-utilization of health services is the main indicator of the success of health services.

Based on table 2 that from the analysis using the chi-square test obtained p-value of $0.005<0.05$, which means there is a relationship between the facilities with the re-utilization of health services for patients with hypertension in the polyclinic of internal medicine in Datu Sanggul Regional Hospital Rantau. Facilities can improve the re-utilization of hypertension health services where the facilities available and completed mostly at the polyclinic of internal in Datu Sanggul Regional Hospital Rantau, by 99 people (93.40\%) see the type of tensimeter in the polyclinic of internal medicine o measure blood pressure in patients hypertension. Because hypertension is a disease that requires longterm therapy, it requires patient compliance in undergoing treatment to control blood pressure and reduce the risk of complications, where complete facilities can be a motivation to re- 
utilization health services for hypertensive patients.

Based on table 2 that from the analysis using the chi-square test obtained a p-value of $0.698>0.05$, which means there is no relationship between the infrastructure and the utilization of health services for patients with hypertension in the polyclinic of internal medicine in Datu Sanggul Regional Hospital Rantau. When the research was underway the initial transition from the prevention of the COVID-19 pandemic to social-physical distancing was implemented to be carried out by all people as part of the health protocol, especially those requiring health services in hospitals, so that specialist doctors did not use infrastructure for examination rooms and actions as part of supporting activities in a service process at the clinic, where specialist doctors only conduct more in-depth history to patients. Also, respondents do not pay too much attention to the type of infrastructure/facilities of examination rooms and actions.

Simultaneously the factors that influence the re-utilization of health services (Y) are completion time (X1), service products (X2) and facilities (X3). In this research, service product (X2) is the most dominant variable related to the re-utilization of health services in the disease clinic in Datu Sanggul Regional Hospital Rantau with a significance value of 0.002 . From the regression model, it was found that the most dominant factor related to the re-utilization of health services in the polyclinic of internal medicine in Datu Sanggul Regional Hospital Rantau was a service product with an $\operatorname{Exp}(\mathrm{B})$ value of 26.587 times greater than other variables. It describes that hypertensive patients visiting the polyclinic of internal medicine want to get health services related to hypertension he suffered. This study is in line with Masri, et al (2017), which explains that there is a significant relationship between product factors, location, promotion, and hospital staff and patient satisfaction in the outpatient room. As one of the most important hospital products that must be considered is in accordance with the needs of patients because the product is something that the hospital can offer to meet the needs of patients and if the product is good it can satisfy the patient (9).

Facility (X3) is related to the re-utilization of health services with a significance value of 0.150 where the with OR 2.293, the facilities with an increase of 1 unit will increase the re-utilization of health services by hypertensive patients by 2.293 times. The highest facility factor for complete types of facilities is tensimeter because hypertensive patients re-utilization more to the polyclinic in controlling blood pressure using tensimeter devices, according to Anderson (1998) in Suratman (2014) defines enabling factors as enabling factors, namely factors that may make sick people use health services. These factors include the family's economic status, access to existing health care facilities. The availability of health service facilities will affect the quality of health status and the status of health problems that occur in the working area (10).

Finally, the completion time (X1) is related to the re-utilization of health services in the polyclinic of internal medicine in Datu Sanggul Regional Hospital Rantau with a p-value of 0.025 where the $\operatorname{Exp}$ (B) value is only 0.35 because the completion time is directly proportional to the patient's willingness to re-utilization health services in patients hypertension in internal medicine polyclinics. It can be said that patients who feel the completion time is not timely but still feels comfortable and suitable to reutilization their health services because this can be influenced by their perceptions and impressions after receiving the services provided such as good service products and complete facilities for the examination of hypertension. By the Ministry of Health (2016) that the category of the distance between waiting time and estimated examination time can satisfy or not satisfy the patient is when the patient comes from coming to the counter, queuing and waiting for a call to the general poly to be anamnesis and examined by nurses, doctors, or midwives $>90$ minutes (old category), 30 60 minutes (medium category) and $\leq 30$ minutes (fast category). Where waiting time is the time needed from the patient registering until served by a specialist. The purpose of waiting time is the availability of specialist outpatient services on weekdays at each hospital that is easily and quickly accessed by patients (11).

\section{CONCLUSION}

1. There is a relationship between the completion time and the re-utilization of health services for hypertensive patients in the polyclinic of internal medicine in Datu Sanggul Regional Hospital Rantau.

2. There is a relationship between the facilities and the reutilization of health services for hypertensive patients in the polyclinic of internal medicine in Datu Sanggul Regional Hospital Rantau.

3. There is no relationship between infrastructure and the reutilization of health services for hypertensive patients in the polyclinic of internal medicine in Datu Sanggul Regional Hospital Rantau.

4. Service product is the most dominant variable related to the re-utilization of health services for hypertensive patients in the polyclinic of internal medicine in Datu Sanggul Regional Hospital Rantau

\section{REFERENCES}

1. The Indonesian Basic of Health Research (2018). Riskesdas. Indonesian Ministry of Health Health Development Research Agency 2018. Jakarta: Riskesdas: 2018.

2. __. (2017) The Annual Report of the Datu Sanggul Hospital Rantau 2017. Datu Sanggul Regional Hospital Rantau .

3. Anggraini MT, Rohmani A. (2012) Relationship Satisfaction of Patients with Interests Patients in Re-Utilization of Health Care in Family Physician Practice. J Unimus.

4. Permenpan-RB No. 14. (2017) Guidelines for the Preparation of a Public Satisfaction Survey for Public Service Provider Units. The Republic of Indonesia. Jakarta.

5. _. (2018) Datu Sanggul Regional Hospital Rantau Satisfaction Survey 2018. Datu Sanggul Regional Hospital Rantau.

6. Silitonga TM (2018) Factors That Influence of Long Witing Time of Outpatient at The Hospital of Saint Elizabeth Batam Year 2016. AARSI.

7. Natarini LWE. (2018) Analysis of Service Quality Gaps Based on Patient Satisfaction with Neurology Polyclinic at RS Bhayangkara Surabaya. J Adm Kes Indo. 6 (2). Doi: 10.20473/Jaki.V6i2.2018.75-82.

8. Wulandari C., Ahmad LO, Saptaputra S. (2016) Factors that Associated with the Use of Service Health on UPTD PHC Langara District of Wawonii 
Eastern District Konawe Islands Year 2016. J Im Public Health. Vol.1, No.3. E Issn 2502-731x.

9. Saragih M, Pardede JA, Sijabat F. (2017) Factors Mix Marketing that Associated with Satisfaction of Patient. Idea Nursing Journal. Vol. VIII No. 2

10. Suratman. (2014) Relationship Between Enabling and Reinforcing Factor Against Interests Medication Society in Working Region of Banjarnegara 2 Community Health Center. Thesis. Muhammadiyah University, Purwokerto.

11. Republic of Indonesia Ministry of Health. (2016) Health Care Minimum Standard Care for Hospital. Jakarta: Indonesian Ministry of Health.

\section{AUTHORS}

First Author - Akhmad Munawar Fu'adi Master of Public Health, Faculty of Medicine, Lambung Mangkurat University, Indonesia.
Second Author - Roselina Panghiyangani, Department of Biomedicine, Faculty of Medicine, Lambung Mangkurat University, Indonesia.

Third Author - Fauzie Rahman, Department of Health Care Management, Public Health Study Program, Faculty of Medicine, Lambung Mangkurat University, Indonesia.

Fourth Author - Husaini, Master of Public Health, Faculty of Medicine, Lambung Mangkurat University, Indonesia.

Fifth Author - Meitria Syahadatina Noor, Department of Public Health, Faculty of Medicine, Lambung Mangkurat University, Indonesia.

Correspondence Author - Akhmad Munawar Fu'adi Master of Public Health, Faculty of Medicine, Lambung Mangkurat University, Indonesia, email: adi.artaty@gmail.com 